\title{
The outcome of mesenchymal stem cells therapy for experimental toxoplasmosis
}

\author{
Original \\ Samia E Etewa ${ }^{1}$, Abd-Allah A Al-Hoot ${ }^{2}$, Shimaa M Abdelmoaty ${ }^{2}$, Samira M \\ Article \\ Mohammad', Howayda SF Moawad', Mohamed H Sarhan', Sara A Abdel- \\ Rahman $^{1}$, Mahmoud A El-Shafey ${ }^{3}$, Eman Z Abd El-Monem ${ }^{2}$ \\ Departments of Medical Parasitology ${ }^{1}, Z^{2}$ oology $^{2}$ and Clinical Pathology ${ }^{3}$, Faculties of Medicine \\ and Science, Zagazig University, Zagazig 44519, Egypt
}

\begin{abstract}
Background: Toxoplasmosis is considered one of the widest spread parasitic infections that affects approximately one third of human population. The formation of resident tissue cysts in chronically infected hosts is a challenge as none of the available drugs is capable of eradicating encysted forms of the parasite. Reactivation of dormant infection could be disastrous in immunosuppression states. The application of stem cells (SCs) as promising therapy was tried in some parasitic diseases.

Objective: In this work, SCs therapy was investigated as a therapeutic line in treatment of murine toxoplasmosis. Material and Methods: Avirulent strain of T. gondii (ME49) was used to induce chronic infection in five groups of experimental albino mice \{negative non-infected, non-treated control; positive infected, non-treated control; infected, spiramycin + pyrimethamine + folinic acid (SPF)-treated; infected SCs-treated; infected combined therapy (SPF+SCs)treated\}. Parasitological assessment was by determination of number and size of Toxoplasma cysts in different mice tissues. Descriptive histopathological study of different tissues of mice using hematoxylin and eosin (H\&E) stain, and immunohistochemical (HIC) studies for assessment of $\mathrm{CD}^{+}$in different tissues as a result of toxoplasmosis and the tested therapeutics were performed to investigate the curable role of bone marrow mesenchymal stem cells (BM MSCs).

Results: The outcome revealed significant decrease in number and size of brain tissue cysts on combining SCs with SPF. The group tested by SCs as mono-therapy showed poor curable role, as revealed by results of liver, spleen, eye and brain tissues studies. Same results were confirmed by the recruitment of $\mathrm{CD}^{+}$noted by the immunohistochemical study of brain and spleen sections.

Conclusion: BM MSCs alone have a poor therapeutic role than when combined with SPF for treatment of toxoplasmosis.
\end{abstract}

Keywords: Bone marrow mesenchymal stem cells, immunosuppression, pyrimethamine, spiramycin, toxoplasmosis.

Received: 23 January, 2019, Accepted: 15 March, 2019.

Corresponding Author: Mohamed H Sarhan, Tel.: 00201020260608, E-mail: drsarhan@gmail.com

Print ISSN: 1687-7942, Online ISSN: 2090-2646, Vol. 12, No. 1, April, 2019.

\section{INTRODUCTION}

Toxoplasma gondii is a widespread intracellular parasite capable of invading any nucleated cells in many hosts including humans ${ }^{[1]}$. It infects approximately one third of the world's population ${ }^{[2]}$. Feline family members are the definitive hosts in whom the sexual cycle occurs in the small intestine. In different animals and man, the asexual cycle takes place in their tissues, acting as the intermediate hosts ${ }^{[3]}$.

Human infection by T. gondii occurs by ingestion of bradyzoites in undercooked meat and sporozoites in feline mature oocysts contaminating food or drink. The parasite spreads through the lymphatics and the hepatic portal area to reach the liver, spleen, lung, brain, eyes and other organs. Vertical transmission from mother's placenta to fetus has dangerous results. Blood transfusion and organ transplantation from infected donors are other important sources of transmission ${ }^{[4]}$. In immunocompetent individuals, $90 \%$ of infections are asymptomatic ${ }^{[5]}$, whereas toxoplasmosis either congenital or in immunocompromised persons particularly in AIDS and transplantation patients, is life-threatening ${ }^{[6]}$.

Dormant tissue cysts formation is an immune evasion mechanism that causes damage especially in the retina, brain and muscles. Replicating tachyzoites that disseminate and destroy various tissues rapidly, are the target of effective anti-toxoplasmosis therapeutics. The specific therapeutics are not effective against brain tissue cysts because of their reduced metabolism and blood-brain barrier protection ${ }^{[7]}$.

Spiramycin is produced by Streptomyces ambofaciens and contains three 16-membered macrolide antiparasitic and antibiotic properties. It is the drug of choice against $T$. gondii in pregnancy as it is well tolerated and safe. It reduces the number of infected placentas 
and the risk of congenital toxoplasmosis, and vertical transmission. Pyrimethamine has a synergistic action in treatment of toxoplasmosis that inhibits synthesis of the essential folic acid for Toxoplasma reproduction and survival, through inhibition of dihydrofolate reductase. Folinic acid is usually added to prevent bone marrow suppression by pyrimethamine ${ }^{[8]}$. The search for potent new drugs to treat toxoplasmosis is important as none of the available drugs are completely effective against tissue cysts that are protected from the host's immune system, leading to the possibility of relapse after cessation of treatment ${ }^{[9]}$.

Recently, stem cells (SCs) were found to improve some parasitic diseases like $S$. mansoni by immunomodulation and interleukin-10 production $^{[10]}$. They were also used to treat malaria, trypanosomiasis, leishmaniasis and echinococcosis by improving the function of the tissues of the involved organs ${ }^{[11]}$. Because SCs are precursor cells that can divide and self-renew indefinitely as well as differentiate into one or more cell types ${ }^{[12]}$, they can replace and repair damaged tissues and thus treat or prevent diseases and injury. This type of therapy can be used for treating and preventing many disease ${ }^{[11]}$. The present study was conducted to assess the efficacy and potentiality of SCs therapy for chronic toxoplasmosis in murine models and to investigate the treatment outcome when compared to other therapeutic lines by parasitological, histopathological and immunohistochemical studies.

\section{MATERIAL AND METHODS}

This case control experimental study was carried out in the Medical Parasitology Department (Postgraduate Research Lab) and Medical Biochemistry and Molecular Biology Department (Clinical Chemistry and Stem Cells Lab), Faculty of Medicine, in cooperation with Zoology Department (Parasitology Section), Faculty of Science, Zagazig University, Egypt. The study was conducted during the period from March 2017 to November 2017.

Experimental animals: Eighty healthy lab-bred male Swiss albino mice, 6-8 weeks-old, each weighing 20-25 g were used; 50 mice were included in the study groups and 30 mice were for attaining BM MSCs. They were housed in well ventilated cages and fed standard pellet food with free access to water and maintained under controlled conditions of lighting (12 h light/12 h dark cycle) and temperature $\left(25 \pm 2^{\circ} \mathrm{C}\right)$.

Parasite and infection: Avirulent strain of T. gondii (ME49) was kindly supplied by Medical Parasitology Department, Faculty of Medicine, Alexandria University and maintained in Swiss albino mice in Medical Parasitology Department, Faculty of Medicine, Zagazig University. Infected mice brains were homogenized, and recovered cysts were used to infect mice by intraperitoneal (IP) administration of 10 cysts per mouse ${ }^{[13]}$.

Experimental Design: Five groups each of 10 male Swiss albino mice were used as shown in table (1). Nine weeks post-infection (pi), all mice were sacrificed to perform the intended assessment procedures.

Study assessment: This includes parasitological assessment (number and size of Toxoplasma cysts) in different mice tissues; histopathological assessment (descriptive study) using H\&E stain of different mice tissues; and immunohistochemical assessment of $\mathrm{CD}^{+}$ in different tissues as a result of toxoplasmosis and the tested therapeutics.

BM MSCs procedures: SCs were obtained from bone marrow of thirty Swiss albino male mice after flushing tibias and femurs ${ }^{[16]}$. Viability of cells was verified by trypan blue stain (Figure 1), where transparency indicated viability ${ }^{[17]}$. Then, they were cultured according to Riedhammer et al., ${ }^{[18]}$. Using an inverted microscope, cultured SCs were fusiform in shape and adhesive. CD105 and CD34 surface markers expression was analyzed by flow cytometry in the Clinical Pathology Laboratory, Faculty of Medicine, Zagazig University ${ }^{[19]}$. Second passage of SCs was detached by $0.25 \%$ trypsin, centrifuged at $2000 \mathrm{rpm}$ for $5 \mathrm{~min}$, then washed twice by PBS. Washed cells were incubated with the PE-labeled monoclonal antibody, that binds to cells expressing CD105. Unbound PE-conjugated antibody was then washed from the cells. Cells expressing CD105 were fluorescently stained; the intensity of staining was considered directly proportional to the density of the CD105 protein. Cell surface expression of CD105

Table 1. Study groups

\begin{tabular}{|c|c|c|}
\hline Groups & Characters & Designation \\
\hline 1 & Non infected & Negative control \\
\hline 2 & Infected by $T$. gondii cysts and received no therapy. & Positive control \\
\hline 3 & $\begin{array}{l}\text { Infected by } T \text {. gondii cysts then treated by combination of spiramycin } 100 \mathrm{mg} / \mathrm{kg} / \mathrm{day}^{[14]} \text {, } \\
\text { pyrimethamine } 12.5 \mathrm{mg} / \mathrm{kg} / \text { day and folinic acid } 10-25 \mathrm{mg} \text { orally daily }{ }^{[15]}(\mathrm{SPF})^{*}\end{array}$ & Infected + SPF \\
\hline 4 & Infected then treated by SCs only. & Infected + SCs \\
\hline 5 & Infected by T. gondii cysts then treated by combination of SCs and SPF orally** & Combined therapy \\
\hline
\end{tabular}

* The drugs were provided in powder form and prepared daily as liquid suspensions; following brief sonication, the homogenized suspensions were given at a fixed time daily by oral feeding tube 6 weeks post-infection (wpi) for ten days. ** The same dose and schedule of administration as in groups 3 and 4. 


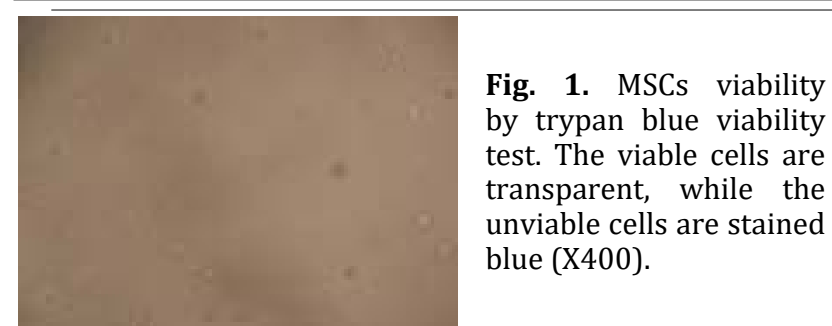

was determined by flow cytometer analysis using 488 $\mathrm{nm}$ wavelength laser excitation ${ }^{[20]}$. According to Louis and Siegel ${ }^{[21]}$, a hemocytometer was used to count and calculate the viable cells: The total number of viable cells $/ \mathrm{ml}=$ Number of viable cells counted/square $\mathrm{X}$ 10,000 dilution factor. The total number of viable cells in the sample $=$ Total number of viable cells $/ \mathrm{ml} \mathrm{X} \mathrm{sample}$ volume in ml. Accordingly, a single dose of 1,000,000 cells/mouse was injected IP in G4 and G5 mice using an insulin syringe $\mathrm{e}^{[22]}$.

Homing of SCs in tissues: This was done using in vivo labeling of SCs with fluorescent PKH26 stain and visualized by a fluorescent microscope according to Li et al., ${ }^{[23]}$. Due to its extremely stable fluorescence, PKH26 is the cell linker dye of choice for in vivo cell tracking studies, particularly when labeled cells are to be followed for periods longer than a few weeks. The kit was supplied by Sigma Aldrich, Egypt.

Sampling: Nine wpi, all study mice were sacrificed by cervical dislocation; at first the eyes were removed, then parts of liver, spleen and brain for:

1.SCs homing detection in liver and brain of BM MSCstested groups ( 4 and 5 , respectively) using fluorescent PKH26 stain.

2.Parasitological study of brain cysts number (semiquantitative) and size using Giemsa stained brain smears according to Lescano et al., ${ }^{[24]}$.

3. Histopathological study of mice liver, brain, eye and spleen tissues using H\&E stained tissue sections according to Abdel Wahab et al., ${ }^{[25]}$.

4.Immunohistochemical study using $\mathrm{CD} 8^{+} \mathrm{T}$ cells marker to detect their presence in infected brain and spleen tissues using the streptavidin-biotin peroxidase complex method. Immunohistochemically (IHC) tissue sections were examined by light microscopy ( $\mathrm{X}$ 400 magnification). Marker expression was recorded by a semi-quantitative grading of brown coloration scheme based upon the percentage of the immunestained area in relation to the total area; low density: $\leq 25 \%$; intermediate density: $>25 \%$ to $\leq 50 \%$; high density: $>50 \%$ of brown coloration ${ }^{[26]}$.

Statistical analysis: Results were analyzed by the Statistical Package for Social Science (SPSS) for windows version 22.0 with student $(t)$ test and analysis of variance (ANOVA) test to evaluate the possible differences between the study groups. $P$ value $<0.05$ was considered significant.

Ethical consideration: All mice were reared and sacrificed according to the international guidelines approved by The Institutional Animal Care and Use Committee, Zagazig University (IACUC-ZU).

\section{RESULTS}

Detection of SCs homing: SCs homing in the liver and brain tissues after their transplantation (groups 4 and 5, respectively) labeled with the PKH26, appeared with strong red auto fluorescence confirming homing (Figure 2).

Results of parasitological study: There was a significant decrease in number and size of Toxoplasma brain tissue cysts in SPF treated mice (G3) compared to infected controls (G2). This decrease was found to a lesser extent in mice received SCs in addition to SPF group (G5). There was insignificant increase in number and size of Toxoplasma brain tissue cysts in mice tested with SCs (G4) compared to G2 (Figure 3 and Tables 2a, $2 b, 3 a$ and $3 b$ ).

Histopathological results: Brain sections from control healthy group (G1) showed normal glial tissue, while those of infected mice (G2) showed heavy infection with Toxoplasma tissue cysts. In infected + SPF treated
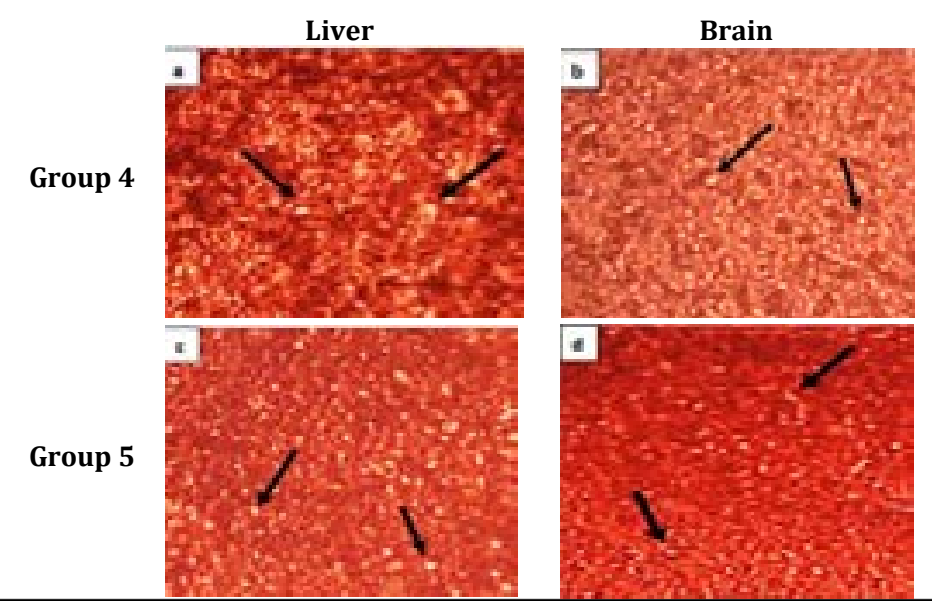

Fig. 2. Many SCs labeled with the PKH26 gave strong auto fluorescence (black arrows) confirming homing of SCs. Group 4: (a) liver, (b) brain, and Group 5: (c) liver, (d) brain (X400). 


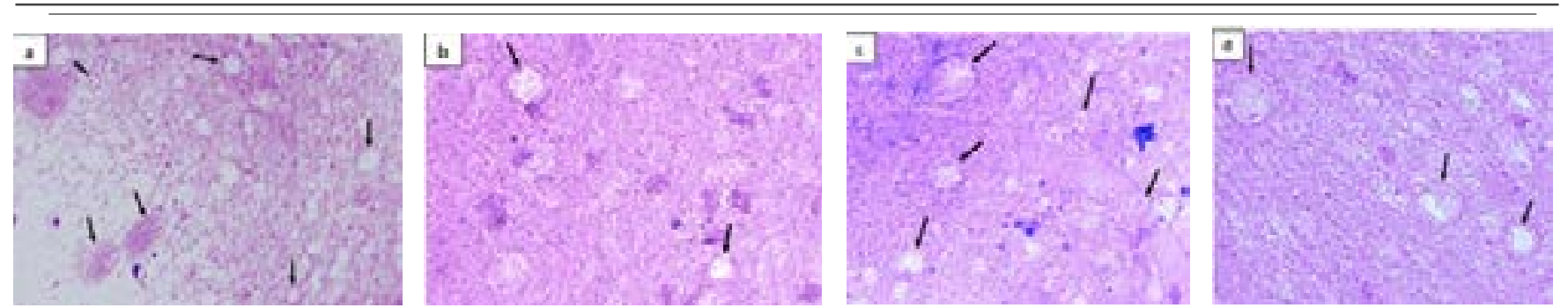

Fig. 3. Photomicrographs of brain tissue cysts of (a) infected control group (G2); (b) SPF treated group (G3) showing decreased number; (c) SCs tested group (G4) showing increased number; (d) SPF + SCs treated group (G5) showing decreased number but lesser than in G3 (Giemsa stain, X1000).

Table 2a. Comparison of micrometer mean values of cyst size in brains of different tested groups by ANOVA test.

\begin{tabular}{|c|c|c|}
\hline \multirow{2}{*}{ Study groups } & \multicolumn{2}{|c|}{ Cyst size $(u)$} \\
\hline & Mean \pm SD & Range \\
\hline Control infected (G 2) $(\mathrm{N}=10)$ & $28.5 \pm 3.8$ & $21-34$ \\
\hline SPF (G3) (N =10) & $14.5 \pm 1.5$ & $12-17$ \\
\hline SCs (G4) (N =10) & $30.6 \pm 4.2$ & $25-37$ \\
\hline SPF + SCs (G5) (N =10) & $18.5 \pm 3.5$ & $13-24$ \\
\hline F- Test (ANOVA) & \multicolumn{2}{|c|}{$F=51.53, P<0.001^{*}$} \\
\hline
\end{tabular}

SD: Standard Deviation. SCs: Stem cells. SPF: Spiramycin, pyrimethamine, folinic acid. * Significant

Table 2b. Comparison of micrometer mean values of cyst size in brains of different tested groups by LSD (least significant difference) test.

\begin{tabular}{lccc}
\hline & Control infected (G2) & SPF (G3) & SCs (G4) \\
\hline SPF+SCs (G5) & $<0.001^{*}$ & $<0.05^{*}$ & $<0.001^{*}$ \\
SCs (G4) & $>0.05 \mathrm{NS}$ & $<0.001^{*}$ & \\
SPF (G3) & $<0.001^{*}$ & & \\
\hline \hline
\end{tabular}

*: Significant, NS: Non-significant.

group (G3), there was significant decrease in numbers of Toxoplasma tissue cysts with areas of hemorrhage and granulation tissues infiltration. Infected mice receiving SCs (G4) showed similar picture to that of G2. Infected + SPF + SCs received group (G5) showed less severe infection by Toxoplasma tissue cysts when compared to that of G2, with areas of hemorrhage and granulation tissues (Figure 4).

Eye sections from G1 (healthy control group) showed normal orbital layers, while those of G2 (infected only) showed many Toxoplasma tissue cysts scattered in-between the orbital tissue layers. G3 (infected + SPF treated group) showed some distorted Toxoplasma tissue cysts and others with intact cyst wall, scattered all over the orbital layers. G4 (infected + SCs tested group) showed many tachyzoites and/ or excysted bradyzoites surrounded by hallows. Eye sections from G5 (infected + SPF + SCs received group) showed more or less rounded tissue cysts, some with distorted wall (Figure 5).

Liver sections from G1 (healthy control group) showed normal hepatic architecture, while those
Table 3a. Comparison of mean values of cysts numbers in brains of different studied group using ANOVA test.

\begin{tabular}{|c|c|c|}
\hline \multirow{2}{*}{ Study groups } & \multicolumn{2}{|c|}{ Cyst number } \\
\hline & Mean \pm SD & Range \\
\hline Control infected (G 2) $(\mathrm{N}=10)$ & $639.8 \pm 88.6$ & $490-771$ \\
\hline SPF (G3) $(N=10)$ & $491.4 \pm 67.8$ & $386-587$ \\
\hline SCs (G4) (N =10) & $662.9 \pm 101.3$ & $510-809$ \\
\hline SPF + SCs (G5) $(N=10)$ & $533.8 \pm 72.5$ & $412-650$ \\
\hline F- Test (ANOVA) & \multicolumn{2}{|c|}{$F=9.45, P<0.001 *$} \\
\hline
\end{tabular}

SD: Standard Deviation. SCs: Stem cells. SPF: Spiramycin, pyrimethamine, folinic acid. * Significant

Table 3b. Comparison of mean values of cysts numbers in brains of different studied groups using LSD test.

\begin{tabular}{lccc}
\hline \hline & Control infected (G2) & SPF (G3) & SCs (G4) \\
\hline SPF + SCs (G5) & $<0.01^{*}$ & $>0.05 \mathrm{NS}$ & $<0.01^{*}$ \\
SCs (G4) & $>0.05 \mathrm{NS}$ & $<0.001^{*}$ & \\
SPF (G3) & $<0.001^{*}$ & & \\
\hline \hline
\end{tabular}

*: Significant, NS: Non-significant.

of G2 (infected only) showed many tissue cysts and macrophages with some hepatocytes showing cloudy swelling. G3 (infected + SPF treated group) showed aggregation of inflammatory cells besides distorted tissue cysts in their livers. G4 (infected + SCs tested group) showed many tissue cysts with areas of hemorrhage and patches of inflammatory cellular infiltration. Liver sections of G5 (infected + SPF + SCs received group) showed areas of hemorrhage together with tissue cysts and many phagocytes scattered all over the field with clear internal inclusions (pseudocysts) of Toxoplasma (Figure 6).

Spleen sections from G1 (healthy control group) showed healthy splenic tissue, while those of G2 (infected only) showed multiple tissue cysts and many pseudocysts of Toxoplasma. G3 (infected + SPF treated group) showed Toxoplasma tissue cysts with clear internal inclusions in their spleens. G4 (infected + SCs tested group) showed tissue cysts with areas of lymphocytic infiltration. Splenic sections of G5 (infected $+\mathrm{SPF}+\mathrm{SC}$ received group) showed tissue cysts surrounded by hallows with areas of hemorrhage (Figure 7). 

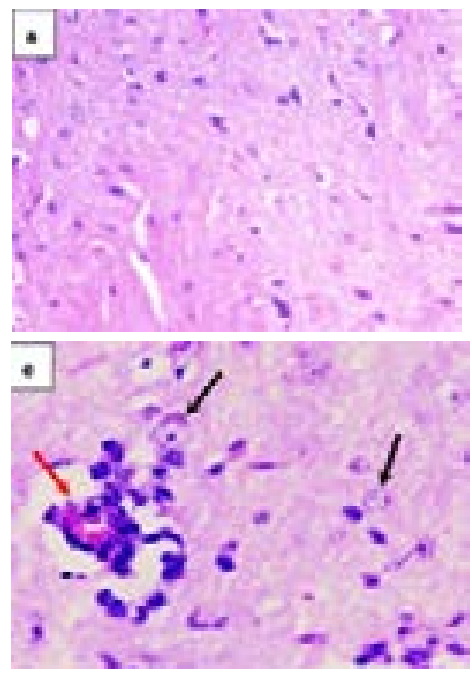
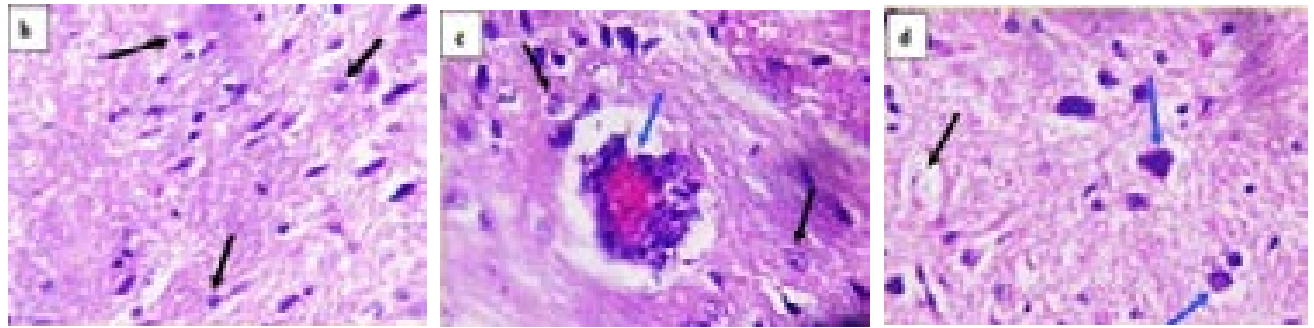

Fig. 4. Brain sections from: (a) control healthy group (G1) showing normal glial tissue; (b) infected only group (G2) showing heavy infection with Toxoplasma tissue cysts (black arrows); (c) infected + SPF treated group (G3) showing decreased number of Toxoplasma tissue cysts (black arrows) with areas of hemorrhage and granulation tissues infiltration (blue arrow); (d) infected + SCs tested group (G4) showing many Toxoplasma tissue cysts scattered all over the field (blue arrows), some are encircled by hallows (black arrows); (e) infected + SPF + SCs received group (G5) showing infection by Toxoplasma tissue cysts (black arrows) with areas of hemorrhage and granulation tissues (red arrow) (H\&E, X400).
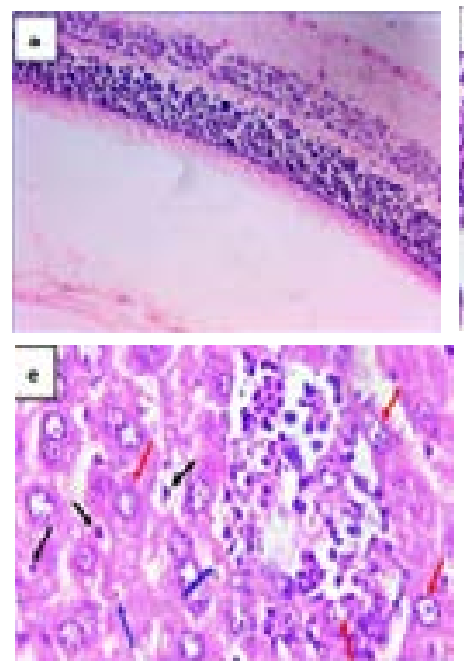
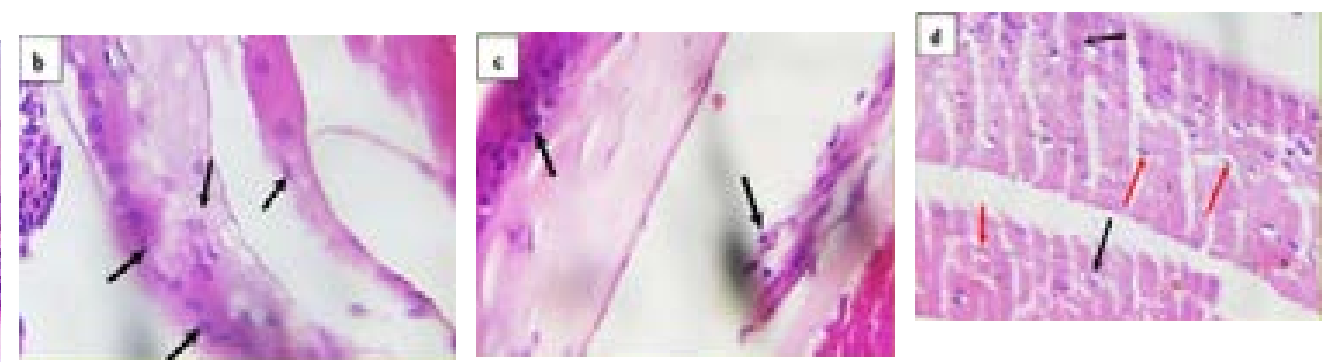

Fig. 5. Eye sections from: (a) G1 (healthy control group) showing normal orbital layers; (b) G2 (infected only) showing many Toxoplasma tissue cysts scattered in-between the orbital tissue layers (black arrows); (c) G3 (infected + SPF treated group) showing some distorted Toxoplasma tissue cysts, others with intact cyst wall, scattered all over the orbital layers (black arrows); (d) G4 (infected + SCs tested group) showing many excysted bradyzoites and/or tachyzoites surrounded by hallows (red arrows); (e) G5 (infected + SPF + SCs received group) showing more or less rounded tissue cysts, some with distorted wall (black arrows) (H\&E, $\mathrm{X} 400)$.
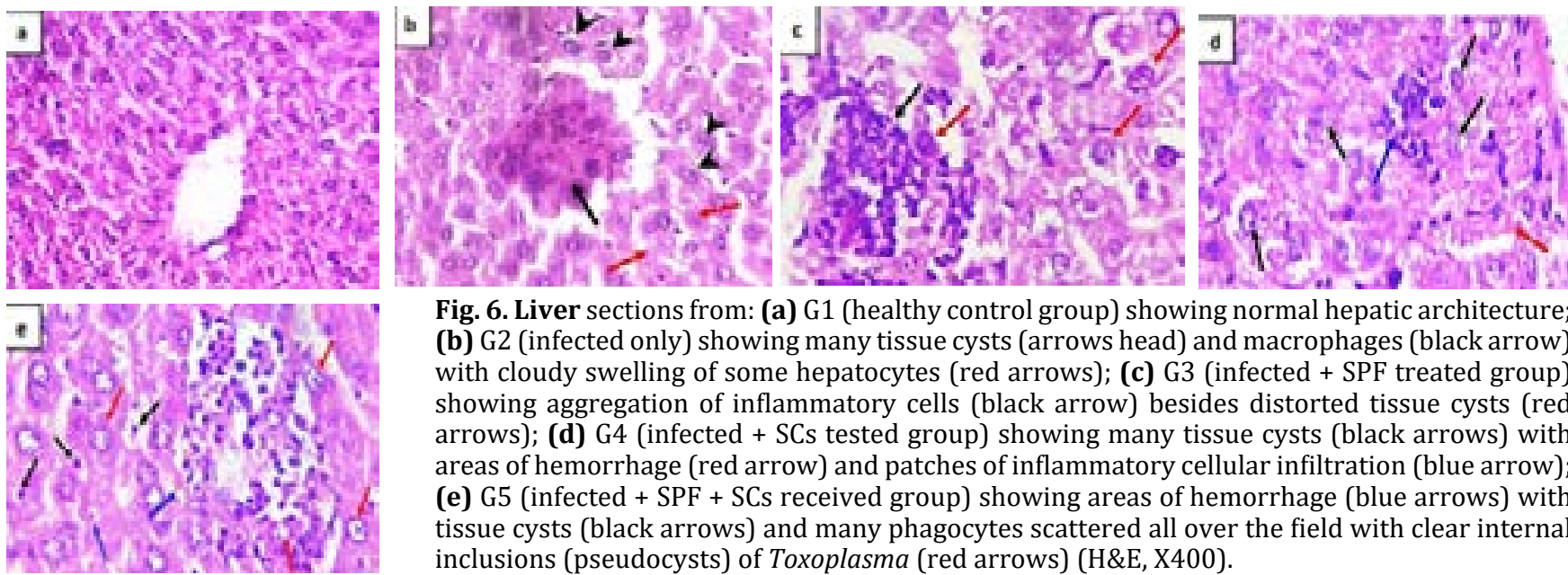

Fig. 6. Liver sections from: (a) G1 (healthy control group) showing normal hepatic architecture; (b) G2 (infected only) showing many tissue cysts (arrows head) and macrophages (black arrow) with cloudy swelling of some hepatocytes (red arrows); (c) G3 (infected + SPF treated group) showing aggregation of inflammatory cells (black arrow) besides distorted tissue cysts (red arrows); (d) G4 (infected + SCs tested group) showing many tissue cysts (black arrows) with areas of hemorrhage (red arrow) and patches of inflammatory cellular infiltration (blue arrow); (e) G5 (infected + SPF + SCs received group) showing areas of hemorrhage (blue arrows) with tissue cysts (black arrows) and many phagocytes scattered all over the field with clear internal inclusions (pseudocysts) of Toxoplasma (red arrows) (H\&E, X400).

Immunohistochemical results: Brain sections from G2 (infected only) showed high density $\mathrm{CD}^{+}$ infiltration; from G3 (infected + SPF treated group), G4 (infected + SCs tested group), and G5 (infected + SPF + SCs received group), sections displayed low density $\mathrm{CD}^{+}$infiltration (Figure 8). On the other hand, spleen sections from G2 (infected only) showed high density $\mathrm{CD}^{+}$infiltration; from G3 (infected + SPF treated group) and G5 (infected + SPF + SCs tested group), sections showed intermediate density $\mathrm{CD}^{+}$infiltration; from G4 (infected + SCs tested group), sections showed low density $\mathrm{CD}^{+}$infiltration (Figure 9). 

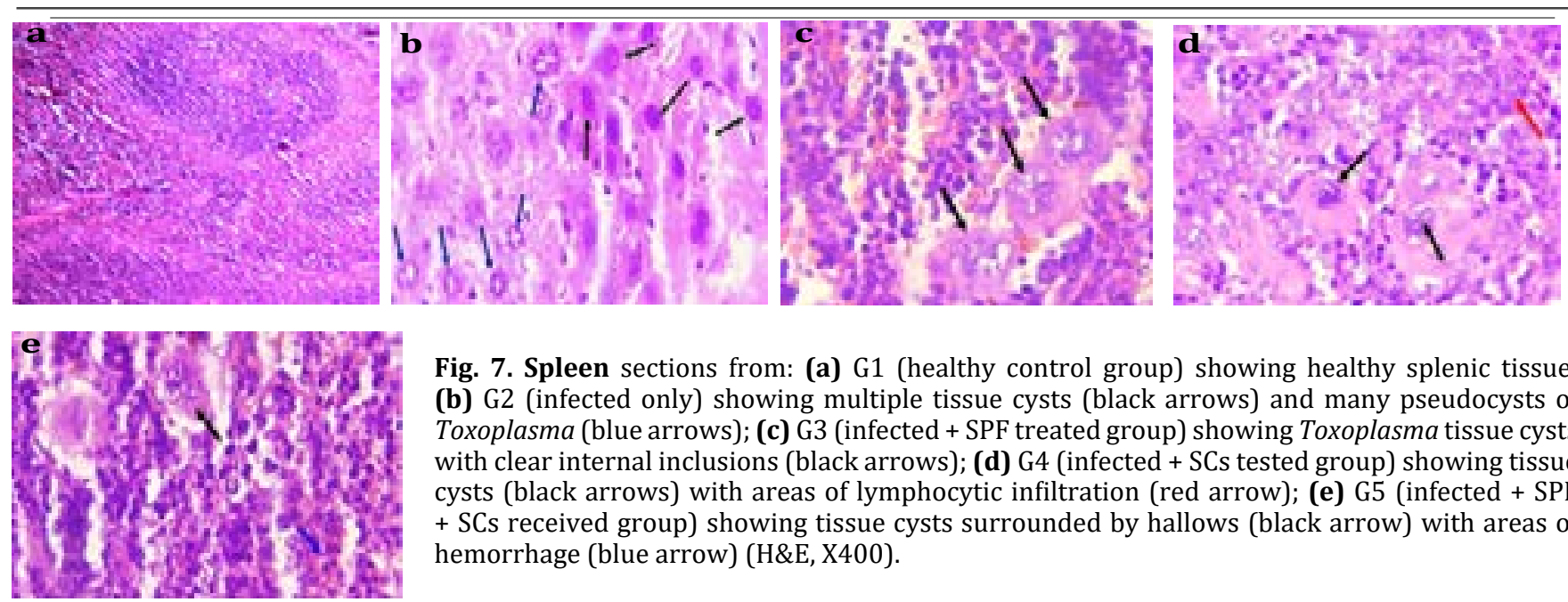

Fig. 7. Spleen sections from: (a) G1 (healthy control group) showing healthy splenic tissue; (b) G2 (infected only) showing multiple tissue cysts (black arrows) and many pseudocysts of Toxoplasma (blue arrows); (c) G3 (infected + SPF treated group) showing Toxoplasma tissue cysts with clear internal inclusions (black arrows); (d) G4 (infected + SCs tested group) showing tissue cysts (black arrows) with areas of lymphocytic infiltration (red arrow); (e) G5 (infected + SPF + SCs received group) showing tissue cysts surrounded by hallows (black arrow) with areas of hemorrhage (blue arrow) (H\&E, X400).
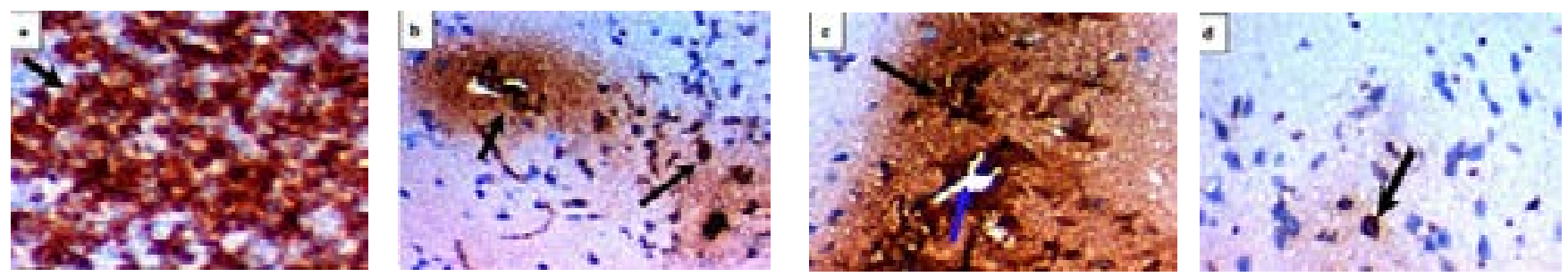

Fig. 8. Brain sections from: (a) G2 (infected only) showing high density CD8+ infiltration with brown coloration (black arrow); (b) G3 (infected + SPF treated group) displaying low density CD8 ${ }^{+}$infiltration (black arrow); (c) G4 (infected + SCs tested group) showing low density CD8 ${ }^{+}$infiltration (brown stained) (black arrow); (d) G5 (infected + SPF + SCs received group) showing low density CD8+ infiltration (black arrow) (IHC, X400).
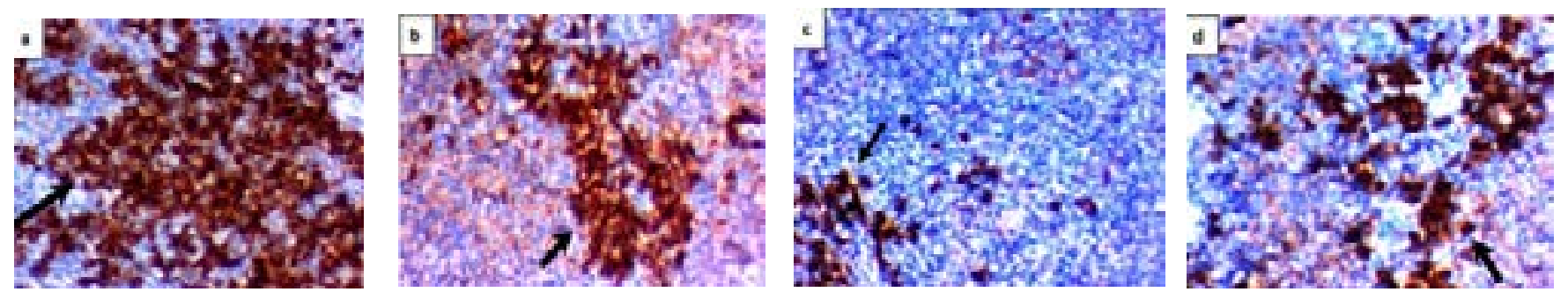

Fig. 9. Spleen sections from: (a) G2 (infected only) showing high density CD8 ${ }^{+}$infiltration (brown stained) (black arrow); (b) G3 (infected + SPF treated group) showing intermediate density CD8 ${ }^{+}$infiltration (brown coloration) (black arrow); (c) G4 (infected + SCs tested group) showing low density CD8+ infiltration (brown coloration) (black arrow), blood vessel (blue arrow); (d) G5 (infected + SPF + SCs tested group) showing intermediate density CD8 ${ }^{+}$infiltration (brown coloration) (black arrow) (IHC, X400).

\section{DISCUSSION}

Toxoplasmosis is an important opportunistic infection in immunocompromised patients ${ }^{[27]}$, while over $80 \%$ of primary T. gondii infections of immunocompetent hosts are asymptomatic ${ }^{[28]}$. Several drugs are used in the treatment for toxoplasmosis primarily against tachyzoites. Those that are commonly used do not eradicate encysted forms because they target the folate pathway of the tachyzoites. The best established regimen is combination of pyrimethamine and sulfadiazine that inhibit parasite folate metabolism. Spiramycin, a macrolide antibiotic, is used to treat infection especially during pregnancy as it has been shown to be non-teratogenic ${ }^{[29]}$. Hence, the search for potent new drugs to treat toxoplasmosis is important as none of the available drugs have a complete curable effect on tissue cysts, that remain hidden from the host's immune system, leading to the possibility of relapse after treatment cessation ${ }^{[9]}$. SCs are unspecialized cells that can be differentiated indefinitely to many specialized cells in the body during life ${ }^{[30]}$. They exhibit a phenotypic ability beyond that of the differentiated cell phenotypes in original tissue i.e. plasticity or transdifferentiation ${ }^{[31]}$.

The best tissue source to use for growth of mesenchymal progenitors is the stroma of bone marrow. So, MSCs were mostly and frequently obtained either by needle aspiration of bone marrow or bone flushing ${ }^{[32]}$. The different growth factors, cytokines and adhesion molecules secreted by MSCs affect the local microenvironment of injured and degenerating target tissue. These secreted bioactive factors 
suppress the local immune system, inhibit fibrosis and apoptosis, enhance angiogenesis, stimulate mitosis and differentiation of tissue intrinsic reparative effect of SCs. These characteristics maintain a positive paracrine effect on the tissue repair and autocrine activities ${ }^{[33]}$. In addition, MSCs are immunologically privileged and allogeneic, and do not induce a proliferative $\mathrm{T}$ cell response. $\mathrm{T}$ cells are important in both immunemediated and ischemic conditions, the capability of MSCs to regulate $\mathrm{T}$ cell role is relevant to their curative and protective impacts ${ }^{[34]}$.

Moreover, MSCs have been successfully applied in treatment of parasitic diseases like Chagas disease ${ }^{[35]}$; and they have already been tried experimentally in schistosomiasis for both treatment ${ }^{[10]}$ and vaccination $^{[36]}$. Accordingly, we were encouraged to test BM MSCs as a potential line of treatment for toxoplasmosis in murine models. Various procedures are known for MSCs seeding in target organs including local infusion and IP systemic injection. The latter route was used in our experiment. The IP method for delivering cells was found to prevent high dilution by blood and accumulation of MSCs within the lung ${ }^{[37]}$. Regardless the route of administration, MSCs have a high passion to migrate and home in the injured sites ${ }^{[38]}$.

In the current study, MSCs were labeled using PKH26 fluorescent lipophilic dye which is referred to as "membrane dyes" and is preferred for its simplicity, and rapid effect. Also it can be applied for almost any type of cells ${ }^{[39]}$. So, in both SCs monotherapy and combined therapy groups, the appearance of fluorescent dots under the fluorescent microscope, in between tissues of brain and liver sections confirmed homing of MSCs. Our results are supported by Seyed et al., ${ }^{[0]}$ who detected migration of PKH26-treated neural SCs to the subjacent cerebral parenchyma and displayed neuronal and astrocytic cell markers. In addition, MSCs have the capability of migration into the tissue from the circulation, possibly responding to signals induced by injuries. MSCs express in vitro chemotaxis toward a variety of wound healing cytokines such as PDGF, TNF $\alpha$, insulin-like growth factor-1 and IL-8 which explains their preferential migration toward injured sites ${ }^{[41]}$.

Regarding the parasite count and size, there was a significant decrease in number and size of Toxoplasma brain tissue cysts in mice treated with SPF (G3) compared to chronically infected controls (G2). This is because spiramycin exerts anti-inflammatory effects through modulation of inflammatory cascade ${ }^{[42]}$. Moreover, it inhibits protein synthesis and subsequent cell growth ${ }^{[43]}$. Also pyrimethamine has a synergistic impact via inhibiting the parasite folic acid synthesis, that is essential for survival and replication ${ }^{[44]}$.

It was noted that there was insignificant increase in size and mean number (30.6u; 662.9) of Toxoplasma tissue cysts in brains of mice with chronic toxoplasmosis following treatment by SCs alone (G4) compared to chronically infected controls (G2) (28.5 u; $639.8 u$ ). Moreover, there was significant increase in size of Toxoplasma tissue cysts in mice receiving both SPF and SCs (G5) (18.5 u) compared to those receiving SPF (G3) $(14.5 \mathrm{u})$ with insignificant increase in mean number of cysts (533.8 and 491.4 respectively). These results can be explained by the claimed immunosuppressive property of SCs causing inhibition of $\mathrm{T}$ helper and cytotoxic $\mathrm{T}$ cells proliferation through multiple pathways $^{[45]}$.

The histopathological examinations of brain tissue of the infected control group (G2) showed wide distribution of tissue cysts without tropism for any specific region, as emphasized by the findings of Dubey et al., ${ }^{[46]}$. Also, T. gondii tissue cysts in brain tissues of infected control mice were with intact cyst wall without distortion, similar to notifications by Waree et al., ${ }^{[47]}$. Fuentes-Castro et al., ${ }^{[48]}$ also recorded the presence of inflammatory infiltration and gliosis around T. gondii cysts in chronically infected mice. In our study, the brain tissue of SPF treated group (G3) showed the presence of a moderate number of Toxoplasma tissue cysts with areas of hemorrhage and tissue infiltration. SCs tested group (G4) showed insignificant increase in the number of Toxoplasma distorted tissue cysts when compared to G2, with areas of fibrosis. Similarly, Etewa et al., ${ }^{[49]}$ in their histopathological study of brain sections of spiramycin treated mice, reported the presence of few numbers of Toxoplasma cysts encircled by mild inflammatory cellular reaction. These findings were explained by Khalaf et al., ${ }^{[50]}$, who attributed these changes to immunosuppression that flares up cerebral toxoplasmosis. In our study, the recorded reaction may be due to the infection itself or the response to the tested SCs. Slight improvement was found in the group receiving both SPF and SCs (G5), represented in brain section by decreased number of tissue cysts as compared to infected control group (G2). The presence of areas of hemorrhage surrounded by granulation tissue is a sign of wound healing, that may be due to the therapeutic efficiency of SPF in controlling infection. In spite of the alleged immunosuppressive effect of SCs, the anti-inflammatory effects of spiramycin succeeded to neutralize the pro-inflammatory activity of $\mathrm{MSCs}^{[51]}$.

In the present study, histopathological examination of eye tissue of infected control mice (G2) showed presence of many Toxoplasma tissue cysts scattered in between the orbital tissue layers surrounded by hallows with definite outlines. These observations resemble the findings of Dubey et al., ${ }^{[4]}$, who detected the presence of retinal tissue cysts in 20 of 23 rats' eyes but without signs of inflammation. In the SPF treated mice (G3), eye tissue showed decreased number of Toxoplasma cysts in orbital tissue layers compared to SCs tested group (G4) and infected control group (G2), which indicates the synergistic effect of the drugs on nucleic acid synthesis in T. gondii, reflected by decrease 
and up to prevention of tissue damage and prevention of partial dissemination of parasitic infection. These findings agree with the clinical test done by Rothova et $a l .{ }^{[52]}$ who found that patients treated with the classical therapy (pyrimethamine and sulfadiazine and corticosteroids) displayed greater decrease in the size of the retinal lesions as pyrimethamine inhibits dihydrofolic acid reductase, and sulfadiazine is a competitive antagonist of $\mathrm{p}$-aminobenzoic acid.

In mice treated with SCs (G4), the eye tissue showed absence of inflammatory signs with the presence of many Toxoplasma organisms. The present observations are comparable to the histopathological study done by Grossniklaus et al., ${ }^{[53]}$ on immunocompromised hosts (AIDS patients) in which they demonstrated necrotic changes of retina and mild inflammatory reaction with tachyzoites involvement of the pigmented epithelium of the retina, choroid, plus their presence in the optic nerve. Eye sections of SPF and SCs treated group (G5) showed the presence of Toxoplasma organisms with distorted wall. This may be attributed to the equilibrium between the therapeutic effect of spiramycin and the immunosuppressive effect of SCs as previously described.

The present histopathological results of liver sections in infected control group (G2) showed many tissue cysts and macrophages with cloudy swelling of hepatocytes; these observations are not different from the findings of Etewa et al., ${ }^{[49]}$ who detected the presence of multiple Toxoplasma tissue cysts encircled by granulomatous reaction with inflammatory cells infiltration mainly lymphocytes, histocytes, and mild fatty degeneration of hepatocytes. The liver tissue of the SPF treated group (G3) showed aggregation of inflammatory cells and distorted tissue cysts, which may be considered as a good sign for the efficiency of the used SPF drug combination that enhanced the proinflammatory and immune-mediated responses and thus promoted parasitized hepatocyte necrosis and apoptosis, thereby strengthening and extending the stimuli for fibrogenesis ${ }^{[54]}$. Liver tissue of SCs tested group (G4) showed insignificant increase in number of tissue cysts with areas of hemorrhage besides inflammatory cell infiltration which may be ascribed to the immunosuppressive action of SCs that may cause reactivation of toxoplasmosis.

The combined therapy (SPF + SCs) treated group (G5) showed slight improvement of the pathological insult caused by Toxoplasma infection compared to infected control group (G2) and SCs tested group (G4) respectively, represented by the presence of many phagocytes and areas of necrosis and inflammatory cells accompanying tissue cysts. This again may indicate the equilibrium between the therapeutic effect of SPF and the immunosuppressive effect of SCs as described previously.
Results of spleen tissue examination of infected control group (G2) showed the presence of tissue cysts in large numbers and pseudocysts of Toxoplasma. El Temsahy et al., ${ }^{[55]}$ revealed the presence of Toxoplasma pseudocysts containing viable tachyzoites in spleen tissue of mice, using experimental infection by virulent RH strain. In SPF treated group (G3), spleen tissue showed decreased number of tissue cysts as compared to control group (G2), attributed to the synergistic effect of the drug (SPF) on nucleic acid synthesis in Toxoplasma. Histopathological results of spleen tissue from SCs tested group (G4) showed more tissue cysts with distortion in a picture like that of G2, probably due to immunosuppressive activity of SCs without evidence of reactivation of infection.

Bhadra et al., ${ }^{[56]}$ reported that $\mathrm{CD}^{+} \mathrm{T}$ cells play a fundamental effector role in controlling chronic toxoplasmosis. Several inflammatory cell types that infiltrate into the site of infection and exert their function during toxoplasmosis are necessary for initiation of $\mathrm{CD}^{+} \mathrm{T}$ cell responses against the parasite ${ }^{[57]}$. Besides, cell to cell interaction between APCs (key regulators of the immune response) and CD8 T cells is the first step for its activation ${ }^{[58]}$. Moreover $\mathrm{CD}^{+} \mathrm{T}$ cells were shown to eradicate brain cysts through their perforinmediated activity in BALB/c mice ${ }^{[59]}$. In the current work, immunohistochemical study of $\mathrm{CD}^{+} \mathrm{T}$ cells in brain and spleen tissues of mice in infected control group (G2) showed high density CD8 ${ }^{+}$infiltration. Our observations agree with those of Schluter et al., ${ }^{[60]}$ and Bhadra et al., ${ }^{[56]}$ who detected increased number of $\mathrm{CD}^{+} \mathrm{T}$ cells around Toxoplasma cysts in brain tissue. $\mathrm{CD}^{+} \mathrm{T}$ cells in brain tissue sections of SPF treated group (G3) showed low density of $\mathrm{CD}^{+}$infiltration, while spleen tissue displayed intermediate density of $\mathrm{CD}^{+}$infiltration. This may be attributed to the antiinflammatory and immune-modulatory properties of the macrolide antibiotic ${ }^{[61]}$. The reduced number of cysts in brain tissue was due to pyrimethamine action, with subsequent reduction of $\mathrm{CD}^{+}$that requires several inflammatory cell types to be initiated. The reduction may also be due to proapoptotic activity of pyrimethamine that was able to reduce the number of $\mathrm{CD}^{+} \mathrm{T}$ cells which induced caspase apoptosis ${ }^{[62]}$. The properties of the used antibiotic were also assessed by $\mathrm{Wu}$ et al., ${ }^{[63]}$ who said that erythromycin and its derivatives inhibit $\mathrm{T}$ lymphocyte proliferation and induce T lymphocyte apoptosis.

Brain and spleen tissues of SCs tested group (G4) showed low density $\mathrm{CD}^{+}$infiltration which agrees with Zheng et al., ${ }^{[64]}$, who found that MSCs preferentially incline the immune response toward Th2 over Th1 by inhibiting the production of TNF- $\alpha$, IFN $-\gamma, \mathrm{CD} 4^{+} \mathrm{T}$ cells (T helper cells) and $\mathrm{CD}^{+}$cytotoxic T cells. Djouad et al., ${ }^{[65]}$ found that MSCs prevented the proliferation of $\mathrm{CD}^{+} \mathrm{T}$ cells within the allogeneic splenocytes. Kugler et al., ${ }^{[66]}$ observed also a significant decrease in number 
of splenic $\mathrm{CD}^{+} \mathrm{T}$ lymphocytes in chronically infected mice by intracellular microorganisms (e.g. virus). This may explain the results of this study when using SCs in Toxoplasma infected mice (G4).

In conclusion, the used methods for evaluation and assessment showed that the outcoming results were in harmony indicating that BM MSCs can't be used as a therapeutic line for toxoplasmosis. This is because of the immunosuppressive impact that flared up the infection as translated by the current findings. Hence, BM MSCs alone have a poor therapeutic role than when combined with SPF in treatment of toxoplasmosis.

Author contribution: SE Etewa, AA Al-Hoot and SM Abdelmoaty conceived and designed the research idea. SM Mohammad, HSF Moawad, MH Sarhan, SA AbdelRahman, MA El-Shafey and EZ Abd El-Monem were responsible for acquisition, analysis and interpretation of resulting data. SM Mohammad, HSF Moawad and MH Sarhan wrote the draft of the manuscript. AA AlHoot and MH Sarhan completed the critical revision of the article. SE Etewa approved the final version for publication.

Conflict of interest: There is no conflict of interest.

Financial support and sponsorship: Nil.

\section{REFERENCES}

1. Schultz TL, Hencken CP, Woodard LE, Posner $\mathrm{GH}$, Yolken RH, Jones-Brando L, et al. A thiazole derivative of artemisinin moderately reduces Toxoplasma gondii cyst burden in infected mice. J Parasitol 2014; 100:516-521.

2. Okada T, Marmansari D, Li ZM, Adilbish A, Canko $\mathrm{S}$, Ueno $\mathrm{A}$, et al. A novel dense granule protein, GRA22, is involved in regulating parasite egress in Toxoplasma gondii. Mol Biochem Parasit 2013; 189(1-2): 5-13.

3. Dubey JP. The history of Toxoplasma gondii: the first 100 years. J Eukaryot Microbiol 2008; 55(6):467-475.

4. Remington JS, Klein JO. Infectious diseases of the fetus and newborn infant. 2010; Philadelphia, PA: Saunders, pp 918-1041.

5. Kravetz JD, Federman DG. Toxoplasmosis in pregnancy. AJM 2005; 118: 212-216.

6. Jones JL, Parise ME, Fiore AE. Neglected parasitic infections in the United States: Toxoplasmosis. Am J Trop Med Hyg 2014; 90(5): 794-799.

7. Weiss LM, Kim K. The development and biology of bradyzoites of Toxoplasma gondii. Front Biosci 2000; 1(5): D391-405.

8. Peyron F, Mc Leod R, Ajzenberg D, ContopoulosIoannidis D, Kieffer F, Mandelbrot L, et al. Congenital toxoplasmosis in France and the United States: one parasite, two diverging approaches. PLoS Negl Trop Dis 2017; 11(2): e0005222.
9. Martins-Duarte ÉS, Lemgruber L, de Souza W, Vommaro RC. Toxoplasma gondii: Fluconazole and itraconazole activity against toxoplasmosis in a murine model. Exp Parasitol 2010; 124(4): 466-469.

10. Abou Rayia DM, Elmarhoumy SM, Ismail HH, Elchennawy FA and Zalata KR. The outcomes of bone marrow stromal cell therapy in schistosomal hepatic fibrosis: an experimental study. J Egypt Soc Parasitol 2017; 47(3):633-642.

11. Aryamand S, Khademvatan S, Diba K, Manafpour $\mathrm{N}$, Abbassi E. Stem cell therapy in the treatment of parasitic diseases. Iran J Med Microbiol 2017; 11(3): 1-9.

12. Chagastelles PC, Nardi NB. Biology of stem cells: an overview. Kidney Int Suppl 2011; 1(3): 63-67.

13. Sylvio M, D'Alessandro AAB, Avelar JB, Vinaud MC, Junior RSL, Bezerra JCB, et al. Experimental toxoplasmosis: evaluation of the hepatic damage in murines. Rev Patol Trop 2014; 43(3): 303-312.

14. Grujić J, Djurković-Djaković 0, Nikolić A, Klun I, Bobić B. Effectiveness of spiramycin in murine models of acute and chronic toxoplasmosis. Int J Antimicrob Agents 2005; 25(3): 226-230.

15. Romand S, Pudney M, Derouin F. In vitro and in vivo activities of the hydroxynaphthoquinone atovaquone alone or combined with pyrimethamine, sulfadiazine, clarithromycin, or minocycline against Toxoplasma gondii. Antimicrob Agents Chemother 1993; 37(11):2371-2378.

16. Pulavendran S, Vignesh J, Rose C. Differential anti-inflammatory and antifibrotic activity of transplanted mesenchymal vs. hematopoietic stem cells in carbon tetrachloride induced liver injury in mice. Int Immunopharmacol 2010; 10: 513-519.

17. Freshney RI. Culture of animal cells: a manual of basic technique and specialized applications, 6th ed. 2010; New Jersey, USA: John Wiley \& Sons Inc.

18. Riedhammer C, Halbritter D, Weissert R. Peripheral blood mononuclear cells: isolation, freezing, thawing, and culture. Methods Mol Biol 2016; 1304: 53-61.

19. Calabro L, Fonsatti E, Bellomo G, Alonci A, Colizzi F, Sigalotti L, et al. Differential levels of soluble endoglin (CD105) in myeloid malignancies. J Cell Physiol 2003; 194:171-175.

20. Lodie, T, Blickarz, C, Devarakonda, T. Systematic analysis of reportedly distinct populations of multipotent bone marrow derived stem cells reveals a lack of distinction. Tissue Eng 2002; 8:739-751.

21. Louis KS, Siegel AC. Cell viability analysis using trypan blue: manual and automated methods. Methods Mol Biol 2011; 740: 7-12.

22. Cho KA, Ju SY, Cho SJ, Jung YJ, Woo SY, Seoh JY, et al. Mesenchymal stem cells showed the highest potential for the regeneration of injured liver tissue compared with other subpopulations of the bone marrow. Cell Biol Int 2009; 33(7): 772-777.

23. Li $\mathrm{P}$, Zhang $\mathrm{R}$, Sun $\mathrm{H}$, Chen $\mathrm{L}$, Liu $\mathrm{F}$, Yao $\mathrm{C}$, et al. PKH26 can transfer to host cells in vitro and vivo. Stem Cells Dev 2013; 22(2): 340-344. 
24. Lescano SA, Amato Neto V, Chieffi PP, Bezerra RC, Gakiya E, Ferreira CS, et al. Evaluation of the efficacy of azithromycin and pyrimethamine, for treatment of experimental infection of mice with Toxoplasma gondii cystogenic strain. Rev Soc Bras Med Trop 2004; 37(6): 460-462.

25. Abdel Wahab RM, Morsy TA, Bahgat AB, Abdel Rahim MI, Essa MH, Al Alfy YE. The histopathological picture of concomitant infection with Leishmania major and Toxoplasma gondii in albino mice. J Egypt Soc Parasitol 1989; 19(1):1-12.

26. Cote SL, Riberio-Da-Silva A and Cuello AC. Current protocols for light microscopy immunohistochemistry. In: Cuello AC, ED. Immunohistochemistry II. John Wiley \& Sons, New York, 1993; 148-167.

27. Munoz M, Liesenfeld 0 , Heimesaat MM. Immunology of Toxoplasma gondii. Immunol Rev 2011; 240(1): 269-285.

28. Robert-Gangneux F, Dardé ML. Epidemiology of and diagnostic strategies for toxoplasmosis. Clin Microbiol Rev 2012; 25(2): 264-296.

29. Foulon W, Villena I, Stray-Pedersen B, Decoster A, Lappalainen M, Pinon JM, et al. Treatment of toxoplasmosis during pregnancy: a multicenter study of impact on fetal transmission and children's sequelae at age 1 year. Am J Obstet Gynecol 1999; 180:410-415.

30. Cruz M, Siden Å, Tasat DR, Yakisich JS. Are all glioma cells cancer stem cells? J Cancer Sci Ther 2010; 2: 100-106.

31. Krause DS. Plasticity of marrow-derived stem cells. Gene Ther 2002; 9:754-758.

32. Conget P, Minguell JJ. Phenotypical and functional properties of human bone marrow mesenchymal progenitor cells. J Cell Physiol 1999; 181: 67-73.

33. Zachar L, Bačenkov D, Soltys J, Rosocha J. Bioactive mediators associated with mesenchymal stem cells-mediated immunomodulation. J Bone Stem Res 2015; 1(2):006.

34. Humphreys BD, Bonventre JV. Mesenchymal stem cells in acute kidney injury. Annu Rev Med 2008; 59:311-325.

35. Vilas-Boas F, Feitosa GS, Soares MB, Mota A, PinhoFilho JA, Almeida AJ, et al. Early results of bone marrow cell transplantation to the myocardium of patients with heart failure due to Chagas disease. Arq Bras Cardiol 2006; 87(2):159-166.

36. Etewa SE, Abd Allah SH, Badawey MSR, Shalaby SM, El-Shal AS, El Shafey MA, et al. The effect of stem cells as an adjuvant on the immunogenicity of a potential anti-schistosomal vaccine in mice. J Egypt Soc Parasitol 2016; 46(3): 693-716.

37. Wang $\mathrm{M}$, Liang $\mathrm{C}, \mathrm{Hu} \mathrm{H}$, Zhou L, Xu B, Wang $\mathrm{X}$, et al. Intraperitoneal injection (IP), intravenous injection (IV) or anal injection (AI)? Best way for mesenchymal stem cells transplantation for colitis. Scientific Reports 2016; 6(1): 30696.

38. Kholodenko IV, Konieva AA, Lupatov AY, Yegorov YE, Yarygin KN. Transplantation of human mesenchymal stem cells and syngeneic macrophages into mice with contusive spinal cord injury. J Tissue Eng Regen Med 2012; 6 (Suppl.1): 86-87.

39. Horan PK, Melnicoff MJ, Jensen BD, Slezak SE. Fluorescent cell labeling for in vivo and in vitro cell tracking. Methods Cell Biol 1990; 33: 469-490.

40. Seyed JS, Ali AA, Asadi-Shekaari M, NematollahiMahani SN, Sheibani V. Investigating the effects of adult neural stem cell transplantation by lumbar puncture in transient cerebral ischemia. Neurosci Lett 2011; 495(1): 1-5.

41. Hemeda H, Jakob M, Ludwig AK, Giebel B, Lang $S$, Brandau S. Interferon- $\gamma$ and tumor necrosis factor- $\alpha$ differentially affect cytokine expression and migration properties of mesenchymal stem cells. Stem Cells Dev 2010; 19(5): 693-706.

42. Tamaoki J, Kadota J, Takizawa H. Clinical implications of the immunomodulatory effects of macrolides. Am J Med 2004; 117 (suppl 9A): 5S-11S.

43. Pfefferkorn ER, Borotz SE. Comparison of mutants of Toxoplasma gondii selected for resistance to azithromycin, spiramycin, or clindamycin. Antimicrob Agents Chemother 1994; 38(1):31-37.

44. Doliwa C, Xia D, Escotte-Binet S, Newsham EL, Sanderson SJ, Aubert D, et al. Identification of differentially expressed proteins in sulfadiazine resistant and sensitive strains of Toxoplasma gondii using difference-gel electrophoresis (DIGE). Int J Parasitol Drugs Drug Resist 2013; 3: 35-44.

45. Duffy MM, Ritter T, Ceredig R, Griffin MD. Mesenchymal stem cell effects on $\mathrm{T}$ cell effector pathways. Stem Cell Res Ther 2011; 2(4):34.

46. Dubey JP, Ferreira LR, Alsaad M, Verma SK, Alves DA, Holland GN, et al. Experimental toxoplasmosis in rats induced orally with eleven strains of Toxoplasma gondii of seven genotypes: tissue tropism, tissue cyst size, neural lesions, tissue cyst rupture without reactivation, and ocular lesions. PLoS one 2016; 11(5): e0156255.

47. Waree P, Ferguson DJ, Pongponratn E, Chaisri U, Sukthana Y. Immunohistochemical study of acute and chronic toxoplasmosis in experimentally infected mice. Southeast Asian J Trop Med Public Health 2007; 38(2): 223-231.

48. Fuentes-Castro BE, Reyes-García JG, ValenzuelaVargas MT, Martínez-Gómez F. Histopathology of murine toxoplasmosis under treatment with dialyzable leukocyte extract. Mem Inst Oswaldo Cruz 2017; 112(11): 741-747.

49. Etewa SE, El-Maaty DAA, Hamza RS, Metwaly AS, Sarhan MH, Abdel-Rahman SA, et al. Assessment of spiramycin-loaded chitosan nanoparticles treatment on acute and chronic toxoplasmosis in mice. J Parasit Dis 2018; 42(1):102-113.

50. Khalaf AM, Hashim MA, Alsharabati M, Fallon $\mathrm{K}$, Cure JK, Pappas P, et al. Late-onset cerebral toxoplasmosis after allogeneic hematopoietic stem cell transplantation. Am J Case Rep 2017; 18: 246-250. 
51. Sánchez-Abarca LI, Alvarez-Laderas I, Díez Campelo M, Caballero-Velázquez T, Herrero C, Muntión S, et al. Uptake and delivery of antigens by mesenchymal stromal cells. Cytotherapy 2013; 15(6): 673-678.

52. Rothova A, Meenken C, Buitenhuis HJ, Brinkman CJ, Baarsma GS, BoenTan TN, et al. Therapy for ocular toxoplasmosis. Am J Ophthalmol 1993; 115: 517 523.

53. Grossniklaus HE, Specht CS, Allaire G, Leavitt JA. Toxoplasma gondii retinochoroiditis and optic neuritis in acquired immune deficiency syndrome. Report of a case. Ophthalmology 1990; 97(10):1342-1346.

54. Hintermann E, Ehser J, Bayer M, Pfeilschifter JM, Christen U. Mechanism of autoimmune hepatic fibrogenesis induced by an adenovirus encoding the human liver autoantigen cytochrome P450 2D6. J Autoimmun 2013; 44: 49-60.

55. El Temsahy MM, El Kerdany EDH, Eissa MM, Shalaby TI, Talaat IM, Mogahed NMFH. The effect of chitosan nanospheres on the immunogenicity of Toxoplasma lysate vaccine in mice. J Parasit Dis 2016; 40(3): 611-626.

56. Bhadra R, Gigley JP, Weiss LM, Khan IA. Control of Toxoplasma reactivation by rescue of dysfunctional CD8+ T cell response via PD-1-PDL-1 blockade. Proc Natl Acad Sci USA 2011; 108(22): 9196-9201.

57. Scharton-Kersten TM, Wynn TA, Denkers EY, Bala $\mathrm{S}$, Grunvald E, Hieny S, et al. In the absence of endogenous IFN- $\gamma$, mice develop unimpaired IL12 responses to Toxoplasma gondii while failing to control acute infection. J Immunol 1996; 157(9): 4045-4054.

58. Johnson LL. A protective role for endogenous tumor necrosis factor in Toxoplasma gondii infection. Infect Immun 1992; 60(5): 1979-1983.

59. Suzuki Y, Wang X, Jortner BS, Payne L, Ni Y, Michie SA, et al. Removal of Toxoplasma gondii cysts from the brain by perforin-mediated activity of CD8+ T cells. Am J Pathol 2010; 176(4): 1607-1613.

60. Schlüter D, Kaefer N, Hof H, Wiestler OD, DeckertSchlüter M. Expression pattern and cellular origin of cytokines in the normal and Toxoplasma gondiiinfected murine brain. Am J Pathol 1997; 150(3): 1021-1035.

61. Itkin IH, Menzel ML. The use of macrolide antibiotic substances in the treatment of asthma. J Allergy 1970; 45(3): 146-162.

62. Pierdominici M, Giammarioli AM, Gambardella $\mathrm{L}$, De Felice $\mathrm{M}$, Quinti I, Iacobini $\mathrm{M}$, et al. Pyrimethamine (2,4-diamino-5-p-chlorophenyl6-ethylpyrimidine) induces apoptosis of freshly isolated human T lymphocytes, bypassing CD95/ Fas molecule but involving its intrinsic pathway. J Pharmacol Exp Ther 2005; 315(3): 1046-1057.

63. Wu DC, Boyd AS, Wood KJ. Embryonic stem cell transplantation: potential applicability in cell replacement therapy and regenerative medicine. Front Biosci 2007; 12: 4525-4535.

64. Zheng ZH, Li XY, Ding J, Jia JF, Zhu P. Allogeneic mesenchymal stem cell and mesenchymal stem celldifferentiated chondrocyte suppress the responses of type II collagen-reactive $\mathrm{T}$ cells in rheumatoid arthritis. Rheumatology (Oxford) 2008; 47(1):2230.

65. Djouad F, Plence P, Bony C, Tropel P, Apparailly $\mathrm{F}$, Sany J, et al. Immunosuppressive effect of mesenchymal stem cells favors tumor growth in allogeneic animals. Blood 2003; 102(10): 38373844.

66. Kugler DG, Flomerfelt FA, Costa DL, Laky K, Kamenyeva O, Mittelstadt PR, et al. Systemic Toxoplasma infection triggers a long-term defect in the generation and function of naive T lymphocytes. J Exp Med 2016; 213(13): 3041-3056. 